
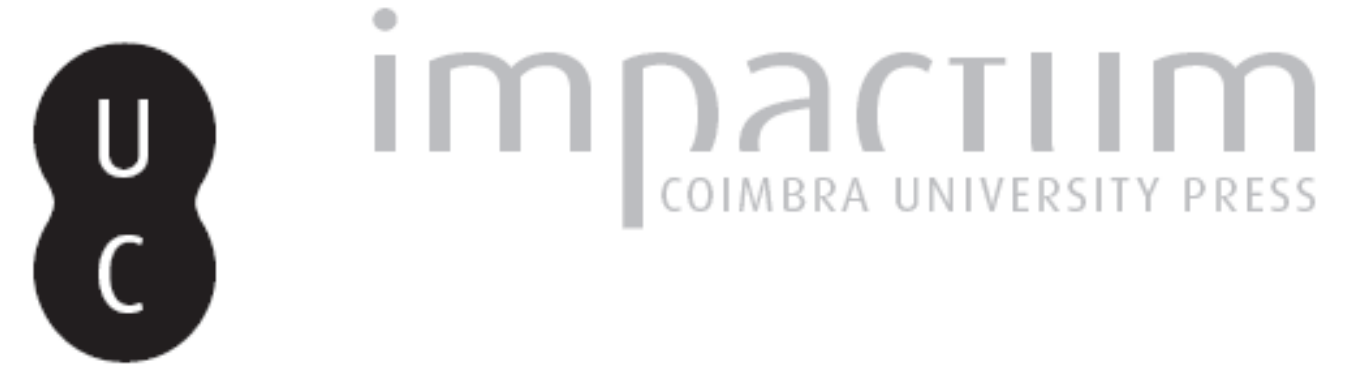

\title{
O elogio da cidade de Goa numa epopeia neolatina do séc. XVII
}
Autor(es): Urbano, Carlota Miranda
Publicado por: Associação Portuguesa de Estudos Clássicos; Instituto de Estudos Clássicos

URL persistente:

URI:http://hdl.handle.net/10316.2/30475

DOI:

DOI:http://dx.doi.org/10.14195/0872-2110_49_12

Accessed : $\quad$ 26-Apr-2023 12:11:18

A navegação consulta e descarregamento dos títulos inseridos nas Bibliotecas Digitais UC Digitalis, UC Pombalina e UC Impactum, pressupõem a aceitação plena e sem reservas dos Termos e Condições de Uso destas Bibliotecas Digitais, disponíveis em https://digitalis.uc.pt/pt-pt/termos.

Conforme exposto nos referidos Termos e Condições de Uso, o descarregamento de títulos de acesso restrito requer uma licença válida de autorização devendo o utilizador aceder ao(s) documento(s) a partir de um endereço de IP da instituição detentora da supramencionada licença.

Ao utilizador é apenas permitido o descarregamento para uso pessoal, pelo que o emprego do(s) título(s) descarregado(s) para outro fim, designadamente comercial, carece de autorização do respetivo autor ou editor da obra.

Na medida em que todas as obras da UC Digitalis se encontram protegidas pelo Código do Direito de Autor e Direitos Conexos e demais legislação aplicável, toda a cópia, parcial ou total, deste documento, nos casos em que é legalmente admitida, deverá conter ou fazer-se acompanhar por este aviso.

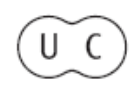




\section{Boletim de}

\section{Estudos Clássicos}

Associação Portuguesa de Estudos Clássicos Instituto de Estudos Clássicos

Coimbra

Junho de 2008 


\section{O Elogio da CidAde de GoA nUMA EPOPEIA NeOlatina DO SÉc. XVII}

O elogio da cidade é um tópico recorrente na Literatura Neolatina e conta com bons exempla na produção literária dos humanistas portugueses. De Cataldo a Damião de Góis, passando por Inácio de Morais, vários humanistas desenvolveram este género ${ }^{1}$. Ora em textos exclusivamente dedicados ao louvor de uma determinada cidade, ora como parte integrante de um discurso, de uma carta, de um poema, de uma biografia, o tópico literário do elogio da cidade é frequente como motivo per se ou a propósito do louvor de uma figura que se pretende elogiar (um mecenas, uma figura régia, um bispo, um santo, etc.). O 'louvor da cidade', pois, fazia parte das variantes do discurso epidíctico, o que, de resto, se enraizava na mais antiga tradição clássica greco-romana. Assim, não é de estranhar que, numa epopeia celebrativa da acção missionária dos jesuítas no Oriente, ${ }^{2}$ nos deparemos com várias ocorrências deste tópico literário, presente também nos modelos da épica renascentista - a épica homérica e virgiliana - nas descrições de cidades ou de reinos, em voga no humanismo contemporâneo, com um mais intenso pendor laudatório.

Cada cidade que merece referência nesta narrativa épica, desde a cidade natal do herói principal (Ponte de Lima) à cidade de Coimbra onde entrou na Companhia de Jesus, entre muitas outras, é pretexto para o elogio que, não raro, resulta no elogio do Reino de Portugal, da Companhia de Jesus e da sua obra missionária em geral.

Também a cidade de Goa merece neste poema uns versos de louvor, na boca do próprio herói que narra em analepse, entre outras coisas, a viagem

1 Como recorda Nair C. Soares no seu trabalho que recomendamos para o estudo do tema: "Cidades ideais e elogio de cidades no Renascimento e em Damião de Góis", Actas do Congresso Internacional Damião de Góis na Europa do Renascimento, Braga, 2003, 583-608.

${ }^{2}$ Referimo-nos ao Paciecidos libri duodecim, da autoria do jesuíta Bartolomeu Pereira, publicado em Coimbra em 1640. Fizemos já alusão a este poema em outros números do Boletim, p.ex. BEC 46, Dezembro 2006, p. 145-150. 
para a Índia e a chegada a Goa. Depois de ter largado precipitadamente da Ilha de S. Lourenço (Madagáscar) o navio onde seguia Francisco Pacheco atravessa os mares em direcção ao rio Indo. É ao fim de oito meses no mar que, enfim, Francisco Pacheco chega a Goa, capital do império português no Oriente, onde vem a encontrar dois dos seus irmãos mais novos que faziam carreira militar, e o seu parente, o P. Diogo Mesquita, que acompanhara a célebre embaixada japonesa à Europa e que desperta nele o interesse por conhecer o Japão.

Vejamos os versos que Bartolomeu Pereira dedica ao louvor desta cidade:

Insula tunc Felix se se uenientibus offert,

Quam, ueluti gemmam isignem, tenet annulus orbis

Crystallo insertam, Tethysque argentea circum

Ambit, et alternis praebetque petique nitores.

Hic Goa, nascentis cunabula roscida solis,

Moenibus elatis, domibusque euecta superbis

Consurgit, caeloque altum diadema recondit.

Hanc olim ualidam gente, et florentibus armis

Munitiam euicit, uastaque in caede cruentam

Terribilis Lysio dedit Albuquertius ensi

Captiuam, iussitque tibi dare colla potenti

Emmanuel, pedibusque tuis offere coronam

Atque iterum attollentem animos, belloque superbo

Elatam, et Lysiae renuentem fraena subegit,

Vt foret Eoi sublimis regia sceptri,

Proregique domus, portusque et meta carinis,

Quae Lysia ex magna longinqua per aequora dites

Aurorae populos, Orientisque arua subirent.

Haec modo iactatam statio fidissima puppem

Excepit, fessisque dedit pia littora nautis.

Vrbe domus media, tollit se se ardua Pauli,

Nostrorum antiqua sedes, haec limina ab undis

Me fessum, errantemque octo super aequora menses

Excipiunt; non ipse tuos domus hospita honores

Ore feram, satis est Pauli quod nomina serues,

Atque animos, titulosque geras, ut maxima cunctas

Iesuadum tu sola domos ingentibus actis 
Exuperes, aliasque tuis uirtutibus aeques;

Hanc cum Xauerii dextra imperiosa locauit,

$\mathrm{Vt}$ foret indigenis, Lysioque ex orbe profectis

Hospitium sublime dedit, decus inclyta tantum

Seruat adhuc, cunctosque domus seruabit in annos.

Hic finis cursus, et meta optata uiarum.

(Paciecidos.... VIII, 508-539)

"Apresenta-se-nos à chegada uma ilha abençoada que o anel do mundo sustenta como uma distinta pedra preciosa incrustada no cristal, e que as águas de prata cingem em volta, ora dando ora ocultando alternado brilho.

Eis Goa, berço orvalhado do sol nascente, que se ergue em elevadas muralhas e, exaltada em soberbos palácios, oculta no céu o seu nobre diadema.

A ela, embora de raça valente e guarnecida de armas florescentes, venceu-a o temível Albuquerque numa grande batalha; fê-la cativa, ensanguentada sob o domínio português e ordenou-lhe que, a vós, D. Manuel, cedesse o jugo, e que a vossos pés colocasse a coroa. E de novo, quando ela, retomando as forças, se entregava a um combate altivo recusando o freio de Portugal, a submeteu, para que viesse a ser a nobre sede do império no Oriente, a morada do Vice-Rei, o porto e a meta para as embarcações que, do grande e longínquo Portugal, atravessando os mares, procuram as ricas nações da Aurora e as terras do Oriente.

Foi este porto fidelíssimo que recebeu o nosso navio debilitado e ofereceu aos marinheiros cansados a costa amiga.

No meio da cidade, ergue-se o grande [Colégio] de S. Paulo, de há muito a casa da Companhia. ${ }^{3}$ Estas portas se me abriram, cansado do mar e de errar sobre as águas oito meses.

Não serei eu, casa hospitaleira, a contar os teus louvores; já é bastante que guardes o nome de S. Paulo, que carregues o valor e a honra, que, sozinha, superes todas as casas dos jesuitas nas suas grandes obras e as iguales com tuas virtudes. Quando a mão poderosa de Xavier te estabeleceu, foi para os indígenas, e para os que viajam de Portugal; a eles te deu como

3 Ou 'antiga casa dos nossos', i.e, dos padres da Companhia de Jesus, a que pertence o narrador. 
sublime hospedagem - ínclita honra que esta casa justamente conserva até hoje, e conservará pelos anos fora.

Era aqui o fim da minha viagem, a meta tão desejada do meu caminho."

Os habituais tópoi do louvor da cidade, o clima e a terra, as suas extraordinárias qualidades para determinados produtos, os habitantes, a forma de governo, entre outros, são omitidos. Trata-se de um elogio breve, mesmo sumário, pois constitui, no plano narrativo, uma pequena digressão.

A descrição da cidade compensa o carácter sumário com a idealização e com o recurso a um breve simile com forte capacidade expressiva: Goa é uma insula felix cingida de águas prateadas como uma pedra preciosa incrustada no cristal. O simile contribui, com os traços idealizantes de uma ilha cercada de águas prateadas, para a caracterização desta cidade quase como mítica, como convinha ao poema épico na esteira do modelo homérico-virgiliano. Como é habitual nestas descrições, os edifícios, pela magnificência da sua construção, são imponentes. O louvor centra-se, então, em dois aspectos, a saber: o valor estratégico da cidade e o seu Colégio de S. Paulo.

A importância estratégica de Goa em relação ao império português reside no facto de constituir uma cidade central e um ponto de passagem e apoio para o avanço da presença portuguesa no Oriente. Goa é um verdadeiro 'espaço europeu fora de portas', a capital do império português na Ásia, o maior porto comercial do Oriente.

Enaltecendo o valor da cidade, como adversário difícil no processo de afirmação do domínio português, o poeta reforça precisamente o valor dos portugueses na afirmação do seu poder.

O Colégio de S. Paulo, por sua vez, é pretexto para louvar a Companhia de Jesus e a obra dos portugueses no império oriental. Embora lhe deva muito, o Colégio, porém, já existia quando S. Francisco Xavier chegou a Goa. Sede do primeiro bispado português no Oriente (Goa mereceria o epíteto de 'Roma do Oriente'), desde cedo a cidade teve um colégio destinado à formação dos nativos dos quais sairia o clero local. Sob o impulso do Vigário Geral Miguel Vaz e de Diogo de Borba, nasceu em 1541 a Irmandade da Santa Fé "cuja empresa [seria] criar em letras e bons costumes moços de todas as nações daquelas partes (...) para que, vindo a ser sacerdotes, tornassem a pregar o Evangelho a suas próprias terras, da conversão das quais, por meio de pregadores de Europa (pois nem para os 
portugueses os havia) de todo se desesperava." ${ }^{4}$ Por rapidamente se concluir da necessidade de uma casa própria onde vivessem em comunidade os jovens estudantes sob a disciplina dos mestres, logo se começou a construir um colégio, confiado ao padroeiro da irmandade, S. Paulo. Nesse colégio, quando S. Francisco chegou a Goa, viviam já cerca de sessenta estudantes sob a orientação de Diogo de Borba. Este colégio vivia sobretudo das rendas de D. João III que acabaria por confiar o seu governo a Francisco Xavier e à Companhia de Jesus.

A partir de então, nesta casa se recolhiam os padres da Companhia que todos os anos partiam de Portugal para a Índia. Por ordem do Padre Francisco Xavier, construíram-se novos edifícios onde se recebiam os moços nativos seculares e educavam em "todos os bons costumes, letras e artes necessárias a um sacerdote e ministro do Evangelho, aprendendo latim, música, filosofia e teologia". O edifício mais antigo onde ficou instalada a Companhia, segundo o P. Lucena, também cresceu: "quase toda a fábrica se tornou a fazer de novo e o mais lustroso é a igreja do Apóstolo São Paulo..."5

Quando Bartolomeu Pereira escreveu estes versos em louvor de Goa e do Colégio de S. Paulo, era já muito clara para a Companhia de Jesus a sua importância em todo o trabalho missionário do Oriente. Já o biógrafo do Padre Francisco Xavier, o P. Lucena que temos vindo a citar, contribuíra para divulgar esta ideia de que o Colégio de Goa era um pulmão da Companhia no Oriente. Na sua obra afirma que tudo o que os padres de S. Paulo (assim eram conhecidos os jesuítas no Oriente) fizeram naquelas paragens, foi obra do Colégio de Goa. E prossegue: "Depois, é verdade que se fundaram novos colégios, casas, muitas residências e já no ano de 1580 tinha a Companhia à sua conta mais de trezentas igrejas por toda a Índia. Mas qual de todas elas não é uma colónia de São Paulo de Goa?"6

Numa epopeia que pretende celebrar a acção da Companhia de Jesus no Oriente, o motivo habitual do louvor da cidade, além de servir para identificar literariamente a obra com o modelo clássico de epopeia, serve de

4 J. Lucena, História da Vida do Padre Francisco de Xavier, transcrição em português actual de Maria Graça Pericão, dir. e coment. de Luís de Albuquerque, 4 vol. (Lisboa, Alfa, 1989) Cf. I, 76-77. A primeira edição desta obra data de Lisboa, 1600 .

5 Ibidem 79.

6 Ibidem 81. 
pretexto e está ao serviço do elogio da Casa da Companhia e da sua vasta acção na empresa missionária do Oriente.

CARLOTA MIRANDA URBANO 